\title{
Pengabdian Masyarakat melalui Penerapan Metode Peer Counselor dengan Pendekatan Spiritual pada Pemrakarsa Kelompok Anti Kekerasan Seksual pada Anak
}

\author{
Nopi Nur Khasanah \\ Prodi D3 Keperawatan, \\ Fakultas Ilmu Keperawatan, \\ Unissula, Semarang 50112 \\ E-mail: nopi.khasanah@unissula.ac.id
}

\author{
Herry Susanto \\ Prodi S1 Ilmu Keperawatan, \\ Fakultas Ilmu Keperawatan, \\ Unissula, Semarang 50112 \\ E-mail: herry_susanto@ymail.com
}

\section{Samsudin \\ Fakultas Agama Islam, Unissula, Semarang 50112 \\ Manager BPI Rumah Sakit Islam Sultan Agung, Semarang, 50112 \\ E-mail: smsdn_salim@yahoo.com}

\section{Article History:}

Received: 2019-10-05

Revised: 2020-03-27

Accepted: 2020-05-31
Keywords:

Anti Child Sex Violance Group

Proponent, Peer Counselor

method, Spiritual Approach

\begin{abstract}
Indonesian child protection commission or Komisi Perlindungan Anak Indonesia (KPAI) data bank showed the case of children as perpetrators as well as victims of sexual violence were very high in comparison to perpetrators or victims of physical and psychic violence. Intervention in schools is necessary to educate the children to behave according to the norms in society. This is the objective of the program and was realized by forming a peer counselor, optimizing the School Health Unit (SHU) services, educating children and parents about the early sex education, and conducting a spiritual approach by formation of psychosocial characteristics. The program was undertaken for approximately 2 months with the methods of training, community education, and advocacy. The program resulted in increased knowledge of early sex education in children (85\%) and the parents (75\%), increase of student PHBS (pretest: 76,9\%; posttest: 92\%), and decrease of children delinquency (pretest: 45\%; Posttest: 30\%).
\end{abstract}

\section{Pendahuluan}

Perlindungan pada anak yang menyeluruh dapat mencakup kesehatan fisik, psikis, maupun sosial ${ }^{1}$. Kesehatan fisik artinya anak terbebas dari penyakit infeksi (seperti diare, thypoid) maupun penyakit non infeksi (seperti anemia). Kesehatan psikis dan sosial (psikososial) artinya anak terbebas dari perilaku meminum alkohol, tawuran, tidak menghormati guru sampai melakukan pergaulan bebas dengan lawan jenis.

Masalah psikososial pada anak menjadi hal yang perlu diperhatikan secara

${ }^{1}$ Kemenkes, Pedoman Pelayanan Kesehatan Anak, 2nd ed. (Jakarta: Bakti Husada, 2010). 
khusus, terutama anak usia sekolah. KPAI ${ }^{2}$ menyajikan data tahun 2016 sebagai berikut: pada kekerasan fisik jumlah anak sebagai pelaku sebanyak 62 anak dan anak sebagai korban berjumlah 84 anak; pada kekerasan psikis jumlah anak sebagai pelaku sebanyak 23 anak dan anak sebagai korban berjumlah 37 anak; sedangkan pada kekerasan sosial jumlah anak sebagai pelaku sebanyak 86 anak dan anak sebagai korban berjumlah 120 anak. Angka tersebut cukup memprihatinkan karena terjadi di negara yang mayoritas muslim.

Dalam ajaran Islam telah sangat jelas memberikan tuntunan dan pedoman tentang bagaimana memperlakukan anak sesuai dengan proporsinya. Selain itu, Islam telah memberikan perhatian yang besar terhadap perlindungan anak-anak ${ }^{3}$. Perlindungan dalam Islam meliputi perlindungan fisik, psikis, intelektual, moral, ekonomi, dan lainnya. Dalam prakteknya dilakukan dengan memenuhi semua hak-hak anak, menjamin kebutuhan sandang dan pangan, menjaga nama baik dan martabat anak, menjaga kesehatan anak, memilihkan teman bergaul yang baik, menghindarkan dari kekerasan, dan lain-lain ${ }^{4}$.

Melindungi anak bukan merupakan kewajiban dari orangtua biologisnya saja, karena anak juga merupakan aset bangsa. Building 5 secara rinci menjelaskan bagaimana upaya dunia internasional merumuskan aturan tentang perlindungan anak. Di Indonesia sendiri, sistem perlindungan anak telah dibuat dalam kerangka hukum. Namun, kebijakan di Indonesia perlu diperkuat untuk mencegah dan menangani kekerasan, perlakuan salah, eksploitasi, maupun penelantaran terhadap anak. K. Artadianti dan A. Subowo ${ }^{6}$ dalam penelitiannya menemukan banyaknya tindakan kekerasan di lingkungan sekolah yang dilakukan oleh guru maupun teman seumuran.

Kekerasan pada anak yang terjadi dapat disebabkan adanya keterbatasan pendidikan dan pemahaman agama yang salah pada orangtua atau keluarga. Bank Data KPAI menunjukkan besarnya angka kekerasan seksual pada anak dibandingkan kekerasan fisik dan psikis. Hal ini dapat terjadi karena kurangnya pendidikan seks di lingkup keluarga, berbicara tentang seks dianggap tabu oleh orangtua, serta banyak orangtua tidak bisa menjelaskan dengan bahasa yang baik tentang pendidikan seks pada anak. Sehingga, anak berusaha mencari jawaban sendiri baik lewat teman maupun internet yang akan berbahaya tanpa pengawasan dari orangtua.

\footnotetext{
2 KPAI, Kasus Perlindungan Anak, 2018.

3 Muhammad Zaki, "Perlindungan Anak Dalam Perspektif Islam," ASAS 6, no. 2 (2014): 1-15.

4 Muh Barid Nizaruddin Wajdi, "Rehabilitasi Anak Berhadapan Dengan Hukum Dalam Perspektif Agama (Studi Kasus Metode Pengembangan Mental Spiritual Anak Lembaga Penyelenggaraan Kesejahteraan Sosial Anak Berhadapan Dengan Hukum (LPKS ABH) Di Nganjuk," JURNAL LENTERA: Kajian Keagamaan, Keilmuan dan Teknologi 3, no. 1 (2017): 188-200.

5 Kinsmen Building, "A World Fit for ALL Children : Including the Rights of Children with Disabilities in The," Children (2003).

${ }^{6}$ K. Artadianti and A. Subowo, "Implementasi Sekolah Ramah Anak (SRA) Pada Sekolah Percontohan Di SD Pekunden 01 Kota Semarang Sebagai Upaya Untuk Mendukung Program Kota Layak Anak (KLA)," Jurnal Isospol (2016): 1-16.
} 
Menurut Freud dalam teori Perkembangan Psikoseksual, fase pertama dari perkembangan anak adalah fase pra-genital 7 . Pada fase ini anak belum terlalu menyadari arti dan perbedaan alat kelamin. Fase ini terbagi atas masa oral (0-1,5 tahun), dan masa anal (1,5 - 3 tahun). Anak baru mulai menyadari adanya perbedaan seks, setelah mencapai usia sekitar 3,5 tahun. Fase ini disebut sebagai masa phalik, yaitu fase dimana kesadaran akan perbedaan alat kelamin antara anak laki-laki dan perempuan memberikan arti yang besar pada kepribadian anak. Rasa ingin tahu yang kuat, membuat anak bertanya-tanya mengenai masalah seks atau bahkan melakukan eksperimen berkaitan dengan alat kelaminnya.

Sesuai dengan pertumbuhan dan perkembangan seksual anak, orangtua hendaknya berperan serta secara aktif dengan membimbing dan mengarahkan anak secara bijaksana untuk bertingkah laku sesuai dengan norma-norma yang berlaku. Minat seksual ini selanjutnya berkembang menjadi berbagai bentuk sublimasi dari kemampuan psikis anak dalam masa latent, yaitu masa dimana berbagai potensi anak masih tersimpan dan belum berfungsi secara penuh ${ }^{8}$. Fase ini berlangsung pada usia sekitar 6-10 tahun. Untuk itu, pembentukan karakteristik psikososial yang baik dengan pendekatan spiritual akan efektif jika diberikan pada anak SD. Selain itu, metode yang digunakan adalah peer conselor (konselor sebaya) yang bertujuan agar pesan-pesan sensitif dapat disampaikan secara lebih terbuka dan santai karena konselor merupakan teman sebaya.

Hasil wawancara dengan guru di SDN Kembangarum 4 menyebutkan adanya kenakalan anak yang kemungkinan terjadi dari latar belakang keluarga, dimana anak yang nakal tersebut berasal dari orangtua yang bercerai, kurang memperhatikan anak, dan tidak memberikan pendidikan seks sejak dini. Terkait sarana prasarana antara lain: UKS berada dalam ruang Perpustakaan dan fungsinya belum optimal, tidak ada kantin sehat sehingga banyak penjual dari luar yang menjual jajanan tidak sehat.

Data Badan Pengawas Obat dan Makanan (BP POM) menandai hampir 40\% pangan jajanan anak sekolah di seluruh Indonesia mengandung bahan berbahaya seperti boraks, formalin dan zat pewarna9. Oleh karena itu, pengelolaan UKS harus maksimal jika ada anak yang mengalami sakit karena konsumsi jajanan tidak sehat. Selain penanganan anak yang sakit, optimalisasi UKS juga sebaiknya berfokus pada pencegahan. Salah satu pencegahan yang efektif adalah dengan meningkatkan pengetahuan dan ketrampilan ibu agar dapat mengawasi kesehatan anak ${ }^{10}$. Hal ini

7 D. Wilson and M. J. Hockenberry, Wong's Clinical Manual of Pediatric Nursing, 8th ed. (St. Louis, Missouri: Mosby Elsevier, 2012).

${ }^{8}$ Vicky R Bowden and Cindy Smith Greenberg, Children and Their Families: The Continuum of Care (Philadelphia: Lippincot Williams \& Wilkins, 2010).

${ }_{9}$ Suparmi, IbM Kelurahan Penggaron Lor Melalui Pemberdayaan PKK Dalam Pembuatan Jajanan Sehat Dengan Pewarna Alami (Semarang, 2013).

10 Anita Rosa Delima, Nugroho Ahmad Riyadi, and Chaerita Maulani, "Upaya Meningkatkan Pengetahuan Dan Keterampilan Ibu Mengenai Kesehatan Gigi Dan Mulut Balita," Jurnal Pengabdian dan 
menjadi landasan bagi tim pendamping untuk memberikan edukasi pada wali murid/orangtua wali.

Permasalahan mitra merupakan suatu keadaan yang ada di SDN Kembangarum 4 Kecamatan Mranggen Kabupaten Demak. Hasil analisis situasi, maka permasalahan yang dihadapi oleh mitra adalah sebagai berikut: (1) adanya anak laki-laki yang berperilaku tidak sopan terhadap anak perempuan; (2) orangtua tidak memberikan pendidikan seks secara dini dengan baik dan bijaksana; (3) anak saling bertengkar dengan mengeluarkan kata-kata 'hewan', saling menendang dan menjewer/mencubit; (4) anak berkata tidak sopan terhadap guru, mencap teman dengan sebutan jelek, tidur saat jam pelajaran; (5) tersedia UKS yang minimalis dan pelayanan kesehatan anak di Sekolah belum maksimal; dan (6) terdapat kantin yang tidak sehat (mudah terkontaminasi oleh debu dan lokasi tidak strategis).

\section{Metode}

Kegiatan yang dilakukan kurang lebih selama 2 bulan dilakukan dengan metode Pelatihan dan pendidikan masyarakat, serta advokasi. Pelaksanaan pengabdian dilakukan koordinasi dengan mitra agar berjalan lancar dan pemberian solusi disesuaikan dengan permasalahan yang ada. Berikut merupakan diagram yang menggambarkan tahapan/langkah pelaksanaan:

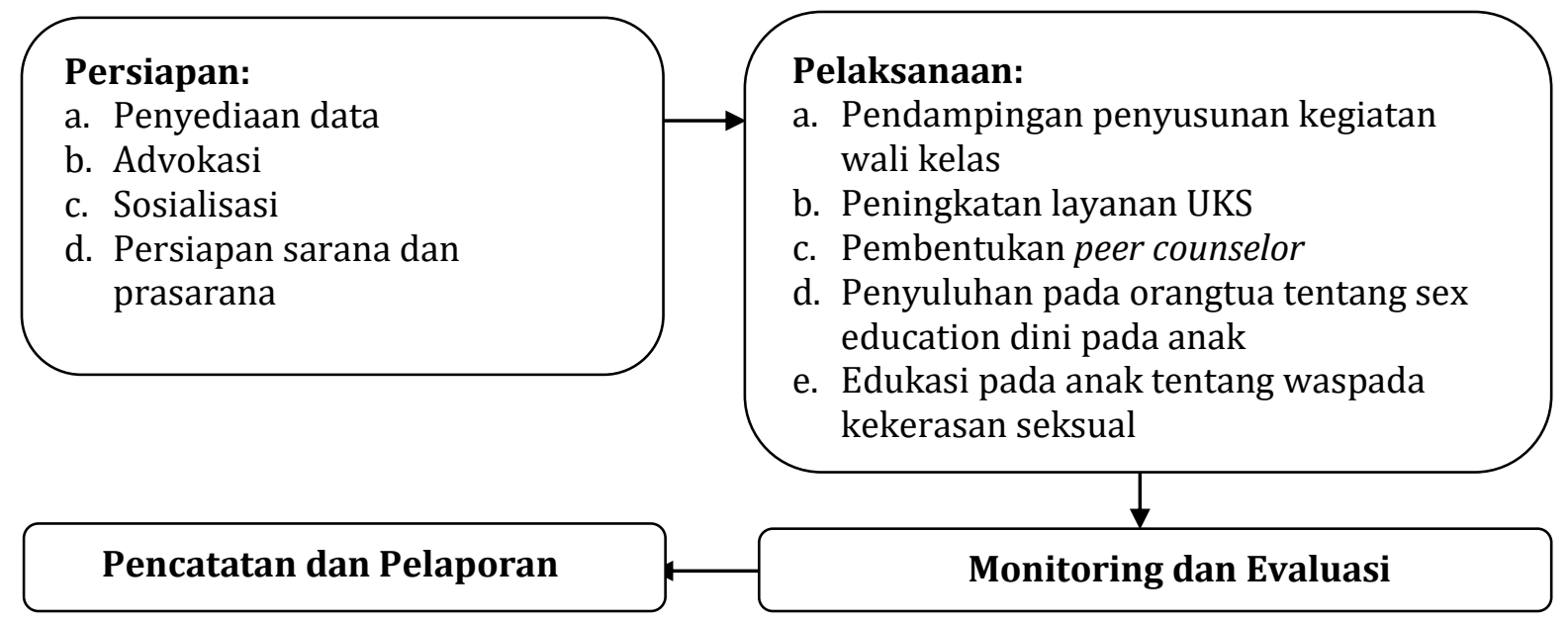

Gambar 1. Tahapan Pelaksanaan Kegiatan Pengabdian

Kerjasama antar tim pengusul dan mitra telah dilakukan, sehingga kegiatan pengabdian berjalan sesuai dengan tujuan dan masalah mitra dapat terselesaikan dengan baik. Berikut pendekatan yang dilakukan oleh pengusul dan mitra untuk saling 
berpartisipasi mencapai tujuan.

Tabel 1. Metode Pendekatan Partisipasi Mitra dalam Pelaksanaan Pengabdian

\begin{tabular}{llcc}
\hline \multirow{2}{*}{ No } & \multicolumn{1}{c}{ Metode Pendekatan } & \multicolumn{2}{c}{ Partisipasi } \\
\cline { 3 - 4 } & & $\begin{array}{c}\text { Tim } \\
\text { Pengusul }\end{array}$ & Mitra \\
\hline 1 & Pendampingan penyusunan kegiatan wali kelas & $\mathrm{X}$ & $\mathrm{X}$ \\
\hline 2 & Peningkatan layanan UKS & $\mathrm{X}$ & $\mathrm{X}$ \\
\hline 3 & Pembentukan peer counselor & $\mathrm{X}$ & $\mathrm{X}$ \\
\hline 4 & $\begin{array}{l}\text { Penyuluhan pada orangtua tentang sex education dini } \\
\text { pada anak }\end{array}$ & $\mathrm{X}$ & $\mathrm{X}$ \\
\hline 5 & Edukasi pada anak tentang waspada kekerasan seksual & & \\
\hline
\end{tabular}

\section{Hasil dan Diskusi}

\section{Pendampingan Penyusunan Kegiatan Wali Kelas}

Kegiatan pendampingan pada wali kelas dilaksanakan dengan seluruh wali kelas satu sampai enam, yang dihadiri juga oleh kepala sekolah SDN Kembangarum 4. Kegiatan berjalan dengan lancar yang dimulai dengan penjelasan dan rencana selanjutnya sesuai dengan kesepakatan bersama Kepala Sekolah. Seluruh wali kelas menyampaikan apresiasi dan menyetujui kegiatan-kegiatan yang akan dilakukan. Setelah penjelasan, beberapa wali kelas mengungkapkan bahwa siswa siswi yang berada di lingkungan SDN Kembangarum 4, beberapa memiliki perilaku yang kurang baik terkait dengan kekerasan seksual. Tiga dari enam guru yang hadir pernah melihat kasus kekerasan seksual antar siswa, seperti mencolek, anak laki-laki memegang payudara anak perempuan, bermain tindih-tindihan, sampai membuka rok anak putri. Namun, masih banyak pula anak-anak yang memiliki prestasi yang baik di lingkungan SDN kembangarum 4. Novi Berliana dan Effendi Pradana ${ }^{11}$ dalam penelitiannya menyebutkan adanya pengaruh yang signifikan antara teman sebaya dengan perilaku hidup bersih dan sehat. Hal ini menjadi landasan pentingnya guru dan juga tim untuk menekan perilaku-perilaku negatif dari beberapa siswa dengan harapan dapat membentuk lingkungan sekolah yang sehat tanpa adanya kekerasan seksual. Gambar 1 menggambarkan situasi diskusi yang relaks sehingga memungkinkan guru untuk menyampaikan kejadian-kejadian yang berkaitan dengan kasus kekerasan seksual dengan nyaman.

11 Novi Berliana and Effendi Pradana, "Hubungan Peran Orangtua, Pengaruh Teman Sebaya Dengan Perilaku Hidup Bersih Dan Sehat," Jurnal Endurance 1, no. 2 (2016): 75-80. 
Pada akhir sesi, wali kelas dan tim pendamping sepakat untuk melaksanakan kegiatan yang membangun kesadaran siswa untuk berperilaku sopan dan santun sesuai dengan norma yang ada. Sebagai monitoring dan evaluasi wali kelas melakukan observasi secara berkala terhadap perilaku hidup bersih dan sehat yang meliputi kepatuhan cuci tangan, gosok gigi malam, buang sampah pada tempatnya, jajan sehat, dan olah raga. Selain itu, observasi juga melihat perilaku sopan terhadap guru dan perilaku santun dengan teman-temannya.

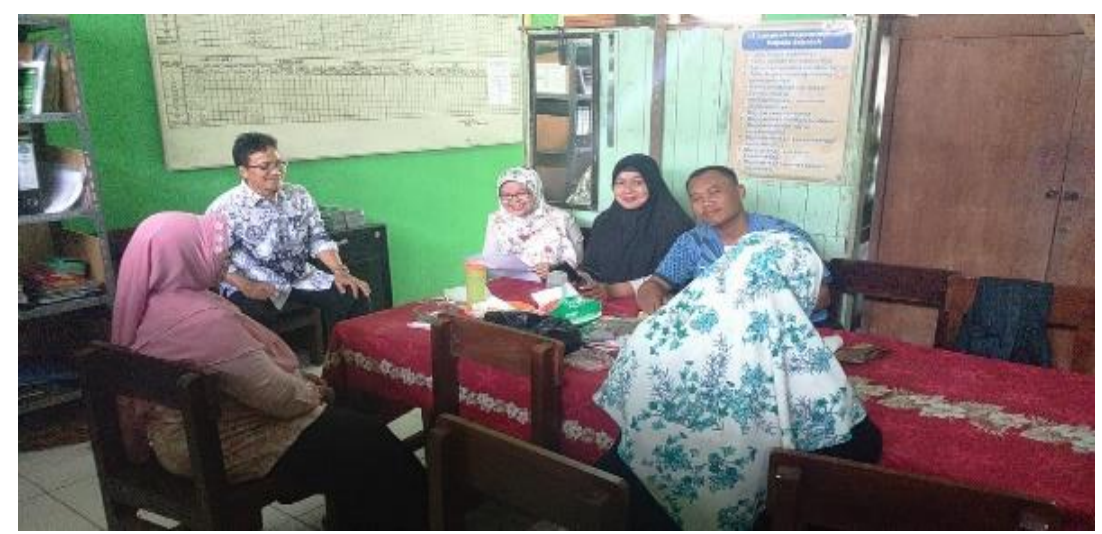

Gambar 2. Suasana Diskusi dengan Wali Kelas

\section{Meningkatkan Layanan UKS}

Peningkatan layanan UKS dilakukan dengan menjadikan peer conselor sebagai kader kesehatan di lingkungan sekolah serta bekerja sama dengan Puskesmas yang membawahi SDN Kembangarum 4. Edukasi terkait PHBS dilakukan untuk meningkatkan kesadaran siswa dalam menciptakan lingkungan yang sehat di Sekolah. Siswa yang menjadi kader kesehatan di Sekolah dan mampu mengajak serta memberikan contoh PHBS yang baik pada teman-temannya merupakan langkah yang efektif dan cukup efisien untuk membentuk PHBS di tatanan Sekolah Dasar ${ }^{12}$. Oleh karena itu, tim berupaya untuk menjadikan KP-AKSA juga sebagai kader kesehatan di sekolah.

Optimalisasi layanan UKS juga dilakukan dengan menambah sarana dan prasarana yang belum mencukupi di lingkungan SDN Kembangarum 4. Alat kesehatan dan obat-obatan yang tersedia di UKS masih sangat minim, sehingga tim berupaya untuk melengkapi dengan penyediaan obat P3K serta peralatan seperti thermometer,

12 M Hayati, “Pengaruh Peer Edukasi Tentang Jajanan Sehat Terhadap Perilaku Anak Usia Sekolah Di Kota Lhokseumawe Provinsi Naggroe Aceh Darussalam” (Universitas Indonesia, 2009); N.N. Islamiyati, "Pengaruh Pemberdayaan Peer Group Terhadap Perilaku Hidup Bersih Dan Sehat Pada Anak Sekolah Dasar Negri 1 Kasihan Ngentakrejo Lendah Kulon Progo" (STIKES Aisyiyah Yogyakarta, 2014); Sri Lestari and Yuli Isnaeni, "Pengaruh Pendidikan Kesehatan Oleh Peer Educator Terhadap PHBS Pada Anak Kelas V SD N 2 Di Jambidan Banguntapan Bantul Yogyakarta” (STIKES 'Aisyiyah Yogyakarta, 2015). 
microtoise, alat penimbangan berat badan, metline, tandu dan tensimeter. Lingkungan sekolah juga membutuhkan beberapa tempat sampah, karena belum cukup tersedia. Saluran air yang tersedia hanya ada dua, sehingga kurang mencukupi untuk digunakan oleh seluruh siswa, oleh karena itu tim pendamping menambahkan sanitasi air terutama untuk cuci tangan seluruh siswa SDN Kembangarum 4. Artadianti dan Subowo ${ }^{13}$ menyebutkan bahwa pentingnya penyediaan sarana prasarana sebagai tahap awal dalam proses implementasi Sekolah Ramah Anak (SRA). Pernyataan tersebut sesuai dengan hasil yang didapatkan oleh tim pendamping, berbagai kegiatan dapat berjalan lancar salah satunya karena sarana prasarana yang telah cukup terpenuhi.

\section{Pembentukan Peer Conselor}

Peer conselor yang dibentuk sebagai KP-AKSA merupakan siswa siswi SDN Kembangarum 4 yang berada di kelas 4, 5, dan 6. Peer conselor yang direncanakan berjumlah 30 anak, pada akhirnya menjadi 53 anak. Hal tersebut karena jumlah tiap kelas yang tidak mencapai 20 anak, sehingga seluruh siswa yang berada di kelas 4, 5, dan 6 diambil sebagai peer conselor. Meskipun jumlahnya melebihi target, seluruh siswa antusias dalam kegiatan pembentukan KP-AKSA yang diselenggarakan di dua ruang kelas. Hal tersebut terbukti dari $100 \%$ kedatangan dan seluruh siswa tampak fokus saat penjelasan oleh tim pendamping.

KP-AKSA diberikan buku panduan peer conselor oleh tim pendamping sebagai upaya untuk mengingatkan kelompok, bahwa mereka adalah agent of change. Buku panduan menjelaskan tentang arti pentingnya teman sebaya, serta bagaimana menjaga teman dari bahaya pornografi. Buku ditulis dengan bahasa yang mudah dipahami oleh anak. Selain itu, untuk menambah semangat anak, Tim memberikan pin sebagai identitas.
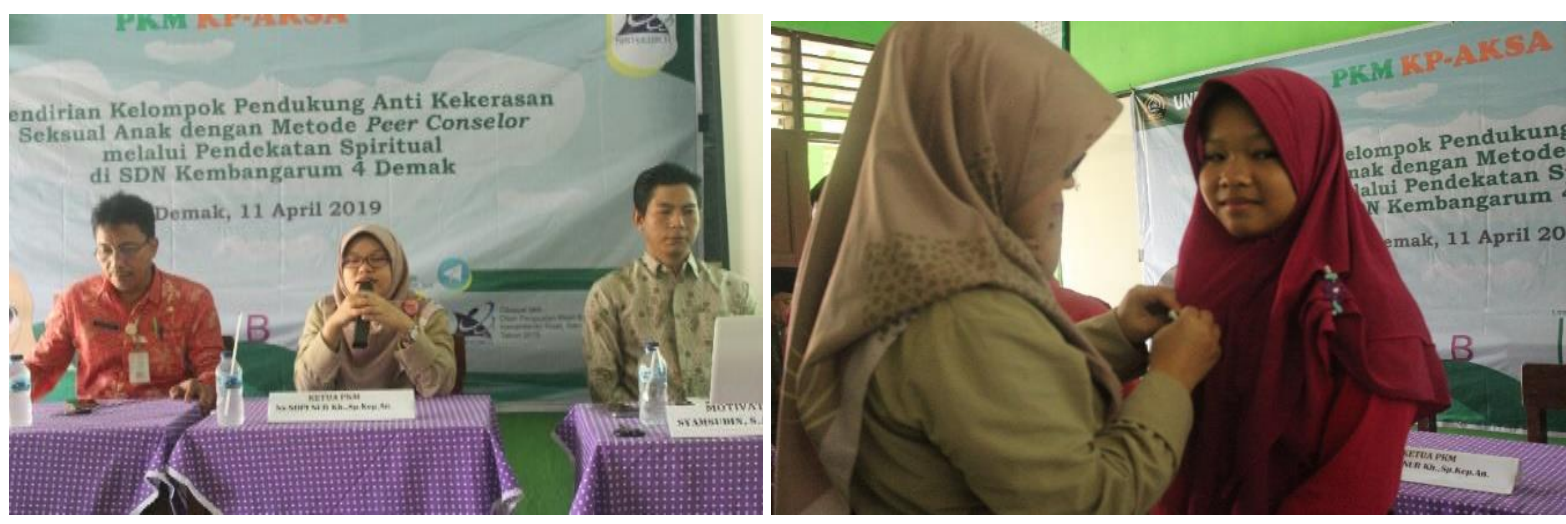

13 Artadianti and Subowo, "Implementasi Sekolah Ramah Anak (SRA) Pada Sekolah Percontohan Di SD Pekunden 01 Kota Semarang Sebagai Upaya Untuk Mendukung Program Kota Layak Anak (KLA).” 
Gambar 2. Penjelasan Tim PKM pada Kegiatan Pembentukan KP-AKSA (Kiri) dan Pemberian Pin sebagai Identitas KP-AKSA (Kanan) 


\section{Penyuluhan pada Orangtua Tentang Sex Education Dini pada Anak}

Pelaksanaan penyuluhan pada orangtua atau wali siswa merupakan kegiatan yang tidak dapat terlaksana. Hal tersebut karena, kondisi sekolah yang tidak memungkinkan untuk mengundang seluruh orangtua. Tim kemudian menyusun sebuah buku pegangan untuk diberikan pada seluruh wali kelas. Buku merupakan kumpulan materi terkait pendidikan seks dini dan bagaimana membentuk generasi soleh.

Bentuk evaluasi yang diberikan adalah dengan meminta anak untuk memberikan surat pernyataan bahwa orangtua telah menerima buku pegangan, serta kuesioner terkait materi telah diisi dan ditanda tangani oleh orangtua. Hasil evaluasi dari isian kuesioner menunjukkan bahwa buku tersebut cukup efektif, hal tersebut terbukti dari hasil kuesioner yang diberikan untuk mengukur pengetahuan orangtua. Rata-rata orangtua menjawab dengan benar sejumlah 8 pertanyaan dari 10 pertanyaan yang dituliskan pada kuesioner. Meskipun penyuluhan tidak dilakukan secara langsung, metode ini cukup efektif untuk meningkatkan pengetahuan orangtua.

D'Addae ${ }^{14}$ menyebutkan bahwa untuk memberikan edukasi pada orang dewasa perlu berganti dari pembelajaran klasik ke pembelajaran modern, dan fokus pembelajaran untuk membantu pembelajar mengkaji ulang makna pembelajarannya. Artinya, metode pembelajaran pada orang dewasa tidak harus dengan bertemu/tatap muka, namun yang terpenting adalah bagaimana orang dewasa memahami tujuan pembelajaran yang diberikan.

\section{Edukasi pada Anak Tentang Waspada Kekerasan Seksual}

Edukasi pada anak diberikan dengan metode atraktif yang menarik untuk anak. Metode tersebut dilakukan dengan mengajak anak bernyanyi, sebelumnya anak mendapatkan materi terkait dengan bahaya pornografi serta bagaimana langkahlangkah untuk menghindarinya. Anak tampak antusias dan mengikuti proses edukasi dengan tenang.

Proses edukasi yang berjalan dengan metode bernyanyi mampu menarik siswa untuk lebih memahami materi yang disampaikan. Nopi Nurkhasanan dan Panji Satriyo ${ }^{15}$ dalam penelitiannya menyebutkan bahwa metode yang efektif untuk merubah perilaku anak adalah dengan story telling (bercerita). Artinya, metode-metode yang ringan dan membawa anak merasa nyaman dapat meningkatkan efektifitas penyampaian materi.

14 D'Addae, "Methods of Teaching Adult Learners: A Comparative Study of Adult Education Programmes in Ghana and South Africa" (University of South Africa, 2014).

15 Nopi Nur Khasanah and Panji Satriyo, "Metode Storytelling Efektif Sebagai Media Edukasi Untuk Meningkatkan Kepatuhan Gosok Gigi Malam,” Jurnal Endurance 4, no. 2 (2019): 303-310. 


\section{Kesimpulan}

Setelah kegiatan pengabdian berlangsung, 90\% permasalahan mitra dapat diselesaikan dan mitra memiliki komitmen dalam keberlangsungan dari kegiatan yang ada tetap dilaksanakan secara kontinu. Adanya peer conselor dan wali kelas sebagai penanggungjawab dalam permasalahan kekerasan seksual dan kenakalan anak, siswa akan semakin nyaman dalam berdiskusi jika ada oknum yang berlaku tidak sopan dan berusaha melakukan pelecehan seksual. Peningkatan pengetahuan peer conselor dilakukan dengan memberikan up date keilmuan tentang kesehatan serta deteksi dini korban kekerasan seksual. Tim pengusul yang menggunakan metode pendekatan spiritual dapat membina anak agar mempunyai kebiasaan baik dan menghasilkan kepribadian yang baik, sehingga perkembangan anak menjadi optimal.

Kegiatan pengabdian selanjutnya diharapkan dapat berfokus pada peningkatan ketrampilan peer counselor yang telah terbentuk. Optimalisasi juga dapat dilakukan dengan meningkatkan pengetahuan dan ketrampilan tenaga pendidik di lingkungan sekolah maupun orangtua siswa.

\section{Daftar Referensi}

Addae, D. "Methods of Teaching Adult Learners: A Comparative Study of Adult Education Programmes in Ghana and South Africa." University of South Africa, 2014.

Artadianti, K., and A. Subowo. "Implementasi Sekolah Ramah Anak (SRA) Pada Sekolah Percontohan Di SD Pekunden 01 Kota Semarang Sebagai Upaya Untuk Mendukung Program Kota Layak Anak (KLA)." Jurnal Isospol (2016): 1-16.

Berliana, Novi, and Effendi Pradana. "Hubungan Peran Orangtua, Pengaruh Teman Sebaya Dengan Perilaku Hidup Bersih Dan Sehat." Jurnal Endurance 1, no. 2 (2016): 75-80.

Bowden, Vicky $\mathrm{R}$, and Cindy Smith Greenberg. Children and Their Families: The Continuum of Care. Philadelphia: Lippincot Williams \& Wilkins, 2010.

Building, Kinsmen. "A World Fit for ALL Children : Including the Rights of Children with Disabilities in The." Children (2003).

Delima, Anita Rosa, Nugroho Ahmad Riyadi, and Chaerita Maulani. "Upaya Meningkatkan Pengetahuan Dan Keterampilan Ibu Mengenai Kesehatan Gigi Dan Mulut Balita." Jurnal Pengabdian dan Pemberdayaan Masyarakat 2, no. 2 (2018): 245-250.

Hayati, M. "Pengaruh Peer Edukasi Tentang Jajanan Sehat Terhadap Perilaku Anak Usia Sekolah Di Kota Lhokseumawe Provinsi Naggroe Aceh Darussalam." Universitas Indonesia, 2009.

Islamiyati, N.N. "Pengaruh Pemberdayaan Peer Group Terhadap Perilaku Hidup Bersih Dan Sehat Pada Anak Sekolah Dasar Negri 1 Kasihan Ngentakrejo Lendah Kulon 
Progo." STIKES Aisyiyah Yogyakarta, 2014.

Kemenkes. Pedoman Pelayanan Kesehatan Anak. 2nd ed. Jakarta: Bakti Husada, 2010.

Khasanah, Nopi Nur, and Panji Satriyo. "Metode Storytelling Efektif Sebagai Media Edukasi Untuk Meningkatkan Kepatuhan Gosok Gigi Malam." Jurnal Endurance 4, no. 2 (2019): 303-310.

KPAI. Kasus Perlindungan Anak, 2018.

Lestari, Sri, and Yuli Isnaeni. "Pengaruh Pendidikan Kesehatan Oleh Peer Educator Terhadap PHBS Pada Anak Kelas V SD N 2 Di Jambidan Banguntapan Bantul Yogyakarta." STIKES 'Aisyiyah Yogyakarta, 2015.

Suparmi. IbM Kelurahan Penggaron Lor Melalui Pemberdayaan PKK Dalam Pembuatan Jajanan Sehat Dengan Pewarna Alami. Semarang, 2013.

Wajdi, Muh Barid Nizaruddin. "Rehabilitasi Anak Berhadapan Dengan Hukum Dalam Perspektif Agama (Studi Kasus Metode Pengembangan Mental Spiritual Anak Lembaga Penyelenggaraan Kesejahteraan Sosial Anak Berhadapan Dengan Hukum (LPKS ABH) Di Nganjuk." JURNAL LENTERA: Kajian Keagamaan, Keilmuan dan Teknologi 3, no. 1 (2017): 188-200.

Wilson, D., and M. J. Hockenberry. Wong's Clinical Manual of Pediatric Nursing. 8th ed. St. Louis, Missouri: Mosby Elsevier, 2012.

Zaki, Muhammad. "Perlindungan Anak Dalam Perspektif Islam." ASAS 6, no. 2 (2014): 115. 